\title{
Comparative study of bilateral axillo-breast approach endoscopic and robotic thyroidectomy: propensity score matching analysis of large multi-institutional data
}

\author{
June Young Choi ${ }^{1,2, *}$, In Eui Bae ${ }^{3, *}$, Hyun Soo Kim4, Sang Gab Yoon ${ }^{4}$, Jin Wook Yi, Hyeong Won $\mathrm{Yu}^{1,2}$, \\ Su-jin Kim ${ }^{2,4}$, Young Jun Chai ${ }^{2,5}$, Kyu Eun Lee ${ }^{2,4}$, Yeo-Kyu Youn ${ }^{6}$ \\ ${ }^{1}$ Department of Surgery, Seoul National University Bundang Hospital, Seongnam, Korea \\ ${ }^{2}$ Cancer Research Institute, Seoul National University College of Medicine, Seoul, Korea \\ ${ }^{3}$ Department of Surgery, Konyang University Hospital, Daejeon, Korea \\ ${ }^{4}$ Department of Surgery, Seoul National University Hospital, Seoul National University College of Medicine, Seoul, Korea \\ ${ }^{5}$ Department of Surgery, Seoul National University Boramae Medical Center, Seoul, Korea \\ ${ }^{6}$ Yeo-Kyu Youn Thyroid Clinic, St. Peter's Hospital, Seoul, Korea
}

Purpose: The aim of this study was to compare the large multi-institutional data of surgical outcomes of bilateral axillo-breast approach (BABA) robotic (RT) and endoscopic thyroidectomy (ET) and to evaluate the merits of robotic thyroidectomy.

Methods: From 2004 to 2015, 1,029 patients underwent BABA ET, and from 2008 to 2015, 2003 patients underwent BABA RT in 3 large volume centers in Korea. Two groups were retrospectively compared in terms of clinicopathologic characteristics, complications, surgical completeness, and long-term outcomes using propensity score matching analysis. Results: Both groups had similar demographic characteristics including age, sex, tumor size, pathologic stage, and hospital stay after matching. Each group had similar rate of transient hypoparathyroidism, however, ET showed significantly higher rate of permanent hypoparathyroidism (ET $5.2 \%$ vs. RT $2.3 \%, P=0.05$ ), and transient vocal cord palsy (ET $14.4 \%$ vs. RT $9.1 \%, P=0.006$ ). Total operation time was longer in the ET group irrespective of surgical extents, including lobectomy $(P=0.016)$, total thyroidectomy $(P=0.031)$, and total thyroidectomy with central lymph node dissection $(P=0.019)$. The rate of patients with off-Tg under $1.0 \mathrm{ng} / \mathrm{mL}$ after 1st ablation was significantly higher in RT than ET group (ET 64.6\% vs. RT 92.7\%, $\mathrm{P}<0.001$ ). In long-term follow-up of cancer patients, 1.4\% experienced recurrence after ET (10 cases), while $0.3 \%$ cases experienced recurrence after RT ( 5 cases $)(P<0.001)$.

Conclusion: Both ET and RT can be safe and effective methods to treat thyroid diseases. However, the application of robotic system may help to overcome the limitations of the instruments and surgeon's skills.

[Ann Surg Treat Res 2020;98(6):307-314]

Key Words: Minimally Invasive surgical procedures, Propensity score, Robotic surgical procedures, Thyroidectomy

\section{INTRODUCTION}

An endoscopic approach for neck surgery was first introduced in 1996 in the concept of avoiding anterior collar incision by Gagner [1]. Thence, various methods for thyroid surgery have been presented [2-5]. However, endoscopic method encloses
Received November 28, 2019, Revised January 30, 2020,

Accepted March 6, 2020

Corresponding Author: Kyu Eun Lee

Department of Surgery, Seoul National University Hospital, 101 Daehak-ro, Jongno-gu, Seoul 03080, Korea

Tel: +82-2-2072-0393, Fax: +82-2-766-3975

E-mail: kyueunlee@snu.ac.kr

ORCID: https://orcid.org/0000-0002-2354-3599
* June Young Choi and In Eui Bae contributed equally to this study as cofirst authors.

Copyright (C) 2020, the Korean Surgical Society

(c) Annals of Surgical Treatment and Research is an Open Access Journal. All articles are distributed under the terms of the Creative Commons Attribution NonCommercial License (http://creativecommons.org/licenses/by-nc/4.0/) which permits unrestricted non-commercial use, distribution, and reproduction in any medium, provided the original work is properly cited. 
several shortages, especially for malignant tumor resection, such as 2-dimensional image, dependency on camera operator's proficiency, and nonflexible instruments consenting limited movement [6,7].

Some of these limitations have been overcome by the use of robotic systems for thyroid surgery. The robot provides a view magnified 15-fold, a 3-dimensional surgical view and flexible arms. Using the robotic system allows the operator to also perform the work of the camera operator simultaneously. The robot facilitates precise manipulations during parathyroid and recurrent laryngeal nerve (RLN) preservation, and central lymph node dissection.

One remote approach is the bilateral axillo-breast approach (BABA), developed in our institutions in 2004 [5]. Since the introduction of BABA robotic thyroidectomy (RT) in 2008 [8], our institutes have used BABA endoscopic thyroidectomy (ET) for over 1,000 patients and BABA RT in over 2,000.

Although BABA ET and RT have been individually compared with conventional open surgery [2,9-11], few studies have directly compared BABA ET with BABA RT [12,13]. The aim of this study was to compare surgical outcomes and completeness of BABA ET and RT, to prove the process of transition from ET to RT is eligible.

\section{METHODS}

\section{Patients}

This retrospective, propensity score-matched study analyzed patients who underwent ET or RT using the BABA method for benign or malignant thyroid diseases between February, 2004, and March, 2015. All operations were performed by surgeons in the departments of surgery at 3 institutions, Seoul National University Hospital, Seoul National University Bundang Hospital, and Seoul National University Boramae Medical Center. The protocol of the study was approved by the Institutional Review Board of Seoul National University Bundang Hospital (B-1610/366-104). Eligible informed consent was got from the enrolled patients.

Indications for BABA ET included benign thyroid nodules or follicular neoplasms of size $<5 \mathrm{~cm}$ or malignant thyroid nodules at low risk (age $<45$ years, tumor size $<2 \mathrm{~cm}$, and no evidence of local invasion, lymph node metastasis, or distant metastasis), and those who underwent completion thyroidectomy after initial endoscopic or robotic lobectomy. Additionally, indications of BABA RT included Graves' disease, benign thyroid nodules up to $8 \mathrm{~cm}$ in size, male patients, and obese patients. Patients were excluded from ET and RT if they had undergone previous neck surgery, had distant metastasis or definite tumor invasion of adjacent organs, or lesions located in the posterior part of the thyroid gland near the tracheoesophageal groove or Berry's ligament.
Preoperative diagnoses of thyroid nodules were assisted by ultrasound and ultrasound-guided fine-needle aspiration cytology. Computed tomography was performed to evaluate tumor location and cervical lymph node metastasis. All female patients underwent physical examination of the breast to detect breast lumps. Thyroid lobectomy was considered in patients with small $(<1 \mathrm{~cm})$, unifocal, intrathyroidal malignant nodules without radiologically or clinically involved cervical nodal metastases. Most patients with malignant thyroid carcinoma also underwent prophylactic ipsilateral central compartment lymph node dissection. Some patients suspected of having metastases in a few lymph nodes on preoperative imaging also underwent selective lateral neck dissection.

\section{Operative methods}

The procedures used for ET and RT have been described $[6,12,13]$. The first steps of ET and RT were similar. Under general anesthesia, the patient was placed in a supine position, with the neck extended. After draping, landmarks and trajectory lines were drawn on the patient's chest and neck. Hydrodissection, or the subcutaneous injection of epinephrine mixed with $0.9 \% \mathrm{NaCl}$ solution $(1: 200,000)$ under the working space, enabled insertion of 8- to $12-\mathrm{mm}$ ports through incisions of bilateral breast areolae and axillary folds. The flap extended from $2 \mathrm{~cm}$ below the clavicle to the thyroid cartilage superiorly and beyond the medial border of the sternocleidomastoid muscle laterally. The working space was created by insufflating low pressure $(5-6 \mathrm{mmHg})$ carbon dioxide $\left(\mathrm{CO}_{2}\right)$ gas through one of the ports. The midline division between strap muscles was made for ET, whereas additional steps of robot docking were needed for RT. The camera was inserted through the right breast port, and robot arms were equipped with energy devices or graspers (Prograsp and Maryland forceps, Intuitive Surgical Inc., Sunnyvale, CA, USA).

After separating the midline of the strap muscles, the thyroid isthmus was divided with the ultrasonic shears. Each thyroid lobe was dissected, as well as each central lymph node, if necessary, while identifying and preserving the parathyroid glands and RLN. The resected specimen was removed, while wrapped in an endoscopic plastic bag, through the left axillary port. The contralateral lobe was dissected in the same manner. After meticulous hemostasis, the midline was closed with endosutures. For selective lateral neck dissection in RT, the sternocleidomastoid muscle was retracted with a double looped polydioxanone (PDS*II, Ethicon Inc., Cincinnati, OH, USA).

\section{Follow-up}

All patients were followed as out-patients at 2 weeks, 3 months, and 6 months after surgery. RLN function and vocal cord abnormalities were evaluated by video laryngoscopy during the second postoperative week. Patients with vocal cord 
abnormalities were assessed by repeat laryngoscopy until vocal cord function was restored. Transient vocal cord paralysis was defined as the recovery of vocal cord function within 6 months after the operation, whereas permanent vocal fold paralysis was defined as the persistence of the vocal cord abnormality for more than 6 months after surgery.

Serum concentrations of total calcium, ionized calcium, phosphorus, and parathyroid hormone (PTH) were measured to assess postoperative hypoparathyroidism. Transient postoperative hypoparathyroidism while hospitalized was defined as the presentation of hypocalcemic symptoms with serum total calcium level $<8 \mathrm{mg} / \mathrm{dL}$. Permanent postoperative hypoparathyroidism was defined as a prolonged need for an oral calcium supplement and serum PTH level $<15 \mathrm{pg} / \mathrm{mL}$ lasting longer than 6 months.

If warranted, radioactive iodine (RAI) ablation was performed 8-12 weeks after thyroidectomy. Indications for RAI ablation included all patients with stage III and IV tumors; all stage II patients aged $\geq 45$ years; most stage II patients aged $<45$ years, and selected stage I patients with multifocal nodules, nodal metastasis, extrathyroidal extension, or other aggressive histology according to the American Joint Committee on Cancer Cancer Staging 8th edition [14]. Thyroid-stimulating hormone (TSH)-stimulated serum thyroglobulin level (stimulated-Tg) was measured prior to administration of 131I. On the second day after RAI, 131I whole-body scan was performed. TSH-suppressed serum thyroglobulin level (suppressed $\mathrm{Tg}$ ) was measured 3 months after the surgery in patients with differentiated thyroid carcinoma who did not undergo RAI ablation. All cancer patients underwent ultrasound and $\mathrm{Tg}$ annually.

\section{Statistical analysis}

Clinicopathologic characteristics, surgical outcomes, surgical completeness, postoperative complications, and

Table 1. Clinicopathologic characteristics

\begin{tabular}{|c|c|c|c|}
\hline Characteristic & $\mathrm{ET}(\mathrm{n}=1,029)$ & $\mathrm{RT}(\mathrm{n}=2,003)$ & P-value \\
\hline Age $(y r)$ & $38.4 \pm 8.86$ & $39.3 \pm 9.90$ & 0.821 \\
\hline \multicolumn{4}{|l|}{ Sex ratio $(n)$} \\
\hline Male:female & $1: 34.5(29: 1,000)$ & $1: 7.8(227: 1,776)$ & $<0.001$ \\
\hline \multicolumn{4}{|l|}{ Mean tumor size on preoperative USG (cm) } \\
\hline Malignant or suspicious malignant & $1.02 \pm 0.96$ & $0.84 \pm 0.69$ & 0.183 \\
\hline Indeterminate or benign looking & $3.11 \pm 1.38$ & $2.55 \pm 1.43$ & 0.095 \\
\hline \multicolumn{4}{|l|}{ Extent of the operation } \\
\hline Total thyroidectomy alone & $145(14.1)$ & $115(5.7)$ & $<0.001$ \\
\hline Total thyroidectomy with CND & $334(32.5)$ & $1375(68.6)$ & $<0.001$ \\
\hline Total thyroidectomy with LND & $29(2.8)$ & $116(5.8)$ & 0.004 \\
\hline Subtotal or lobectomy & $443(43.1)$ & $367(18.3)$ & $<0.001$ \\
\hline Completion lobectomy & $78(7.6)$ & $29(1.4)$ & $<0.001$ \\
\hline Operation for recurrent disease & $0(0)$ & $1(0.1)$ & NS \\
\hline \multicolumn{4}{|l|}{ Pathologic classification } \\
\hline Papillary cancer & $617(60.0)$ & $1649(82.5)$ & $<0.001$ \\
\hline Follicular variant papillary cancer & $48(4.7)$ & $55(3.0)$ & 0.025 \\
\hline Follicular cancer & $61(5.9)$ & $24(1.2)$ & $<0.001$ \\
\hline Medullary cancer & $1(0.1)$ & $2(0.1)$ & 0.554 \\
\hline Graves' disease & $10(1.0)^{\mathrm{a})}$ & $50(2.5)^{b)}$ & 0.007 \\
\hline Adenomatous goiter & $292(28.4)$ & $230(13.0)$ & $<0.001$ \\
\hline Others & $4(3.9)$ & $4(0.2)$ & 0.559 \\
\hline \multicolumn{4}{|l|}{ AJCC 8th stage } \\
\hline I & $530(72.9)$ & $1367(79)$ & NS \\
\hline II & $27(3.7)$ & $106(6.1)$ & NS \\
\hline III & $181(24.9)$ & $224(12.9)$ & NS \\
\hline IVa & $1(0.1)$ & $5(0.3)$ & NS \\
\hline Number of retrieved central lymph nodes & $3.0 \pm 3.63$ & $5.2 \pm 4.78$ & $<0.001$ \\
\hline Cancer recurrence on follow-up & $10(1.4)$ & $5(0.3)$ & $<0.001$ \\
\hline Hospital stay (day) & $3.3 \pm 0.78$ & $3.2 \pm 0.72$ & 0.784 \\
\hline Follow-up period (mo) & $76.2(6-132)$ & $56.2(5-96)$ & 0.109 \\
\hline
\end{tabular}

Values are presented as mean \pm standard deviation, number $(\%)$, or median (range).

ET, endoscopic thyroidectomy; RT, robotic thyroidectomy; USG, ultrasonography; CND, central neck dissection; LND, lateral neck dissection; AJCC, American Joint Committee on Cancer.

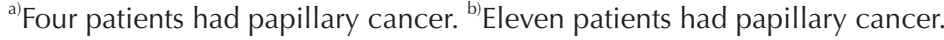


long-term results were compared in the ET and RT groups. To reduce selection and information bias between these groups, propensity score matching was performed based on 9 covariates: mean age; mean tumor size; and percentages of patients who were female, underwent total thyroidectomy, and had thyroiditis, malignancy, multifocality, extrathyroidal extension, and lymph node metastasis. Data were analyzed using IBM SPSS Statistics ver. 22.0 (IBM Co., Armonk, NY, USA), with a P-value less than 0.05 considered statistically significant.

\section{RESULTS}

\section{Clinicopathologic characteristics of the patients}

The mean ages of the ET and RT groups were $38.4 \pm 8.86$ and $39.3 \pm 9.90$ years, respectively (Table 1). RT was performed more frequently in male patients $(\mathrm{P}<0.001)$, in patients who underwent total thyroidectomy with or without lymph node dissection $(\mathrm{P}<0.001-0.004)$, in patients with malignancy $(\mathrm{P}<$ 0.001-0.025), and in patients with Graves' disease ( $P=0.007)$. ET was performed more frequently than RT in patients who underwent completion thyroidectomy (7.6\% vs. 1.4\%, $\mathrm{P}<0.001$ ). The mean number of central lymph nodes retrieved per patient was significantly greater in the RT than in the ET group (5.2 \pm 4.78 vs. $3.0 \pm 3.63, \mathrm{P}<0.001$ ).

\section{Propensity score matching}

Propensity score matching was performed between the 2 groups, and 605 matched pairs were yielded. Nine covariates were used; number of females, mean age, mean tumor size, number of thyroiditis, total thyroidectomy, malignancy, multifocality, extrathyroidal extension, and lymph node metastasis (Table 2). There were no longer significant differences, which observed before matching, in clinicopathologic characteristics between the 2 groups.

Table 2. Result of propensity score matching using 9 covariates

\begin{tabular}{lccc}
\hline \multicolumn{1}{c}{ Matched variable } & ET $(\mathrm{n}=605)$ & $\mathrm{RT}(\mathrm{n}=605)$ & P-value \\
\hline No. of females & $584(96.5)$ & $587(97.0)$ & 0.745 \\
Age $(\mathrm{yr})$ & $39.0 \pm 9.16$ & $37.9 \pm 10.02$ & 0.907 \\
Tumor size $(\mathrm{cm})$ & $1.41 \pm 0.98$ & $1.45 \pm 1.07$ & 0.827 \\
Thyroiditis & $199(32.9)$ & $196(32.4)$ & 0.934 \\
Total thyroidectomy & $382(63.1)$ & $389(64.3)$ & 0.719 \\
No. of malignancy & $408(67.4)$ & $407(67.3)$ & 1.000 \\
Multifocality $^{\mathrm{a})}$ & $251(61.5)$ & $262(64.4)$ & 0.442 \\
Extrathyroidal extension $^{\mathrm{a})}$ & $243(59.6)$ & $264(64.9)$ & 0.136 \\
Lymph node metastasis $^{\mathrm{a})}$ & $156(38.2)$ & $170(41.8)$ & 0.338 \\
\hline
\end{tabular}

Values are presented as number (\%) or mean \pm standard deviation. $\mathrm{ET}$, endoscopic thyroidectomy; $\mathrm{RT}$, robotic thyroidectomy

${ }^{a)}$ In cancer patients.

\section{Comparison of surgical complications}

The matched groups of patients in the ET and RT groups had similar rates of transient hypoparathyroidism after total thyroidectomy (31.7\% vs. 28.0\%, P = 0.303), but the ET group had a significantly higher rate of permanent hypoparathyroidism (5.2\% vs. $2.3 \%, P=0.05$ ) (Table 3). The ET group had a higher rate of transient vocal cord paralysis than the RT group (14.4\% vs. 9.1\%, $\mathrm{P}=0.006)$, but the difference had become statistically insignificant 3-6 months postoperatively $(0.8 \%$ vs. $0.2 \%, \mathrm{P}=$ 0.219 ). The rates of other complications, including postoperative bleeding, tracheal or esophageal injury, and infection, were very low, and the differences not statistically significant. Total operation time was longer in the ET than in the RT group, irrespective of the extent of surgery, including in patients who underwent lobectomy or subtotal thyroidectomy $(P=0.016)$, total thyroidectomy $(\mathrm{P}=0.031)$, and total thyroidectomy with central lymph node dissection $(\mathrm{P}=0.019)$ (Table 4).

\section{Comparison of surgical completeness and recurrence of disease}

Surgical completeness was evaluated by the results of the first RAI ablation. The median stimulated-Tg concentration after the first RAI ablation was $1.55 \mathrm{ng} / \mathrm{mL}$ in the ET group and 0.58 $\mathrm{ng} / \mathrm{mL}$ in the RT group $(\mathrm{P}=0.009$ ) (Table 5). The percentage of patients with stimulated-Tg concentration $<1.0 \mathrm{ng} / \mathrm{mL}$ after the first ablation was significantly higher in the RT than in the ET group (92.7\% vs. $64.6 \%, \mathrm{P}<0.001)$. The median follow-up period was 76.2 months (range, 6-132 months) in the ET group and 56.2 months (range, 5-96 months) in the RT group. Ten of 408

Table 3. Comparison of surgical complications after propensity score matching

\begin{tabular}{lccc}
\hline \multicolumn{1}{c}{ Variable } & ET $(\mathrm{n}=605)$ & $\mathrm{RT}(\mathrm{n}=605)$ & P-value \\
\hline $\begin{array}{l}\text { Transient } \\
\text { hypoparathyroidism }{ }^{\mathrm{a})}\end{array}$ & $121 / 382(31.7)$ & $109 / 389(28.0)$ & 0.303 \\
$\begin{array}{l}\text { Permanent } \\
\left.\quad \text { hypoparathyroidism }{ }^{\mathrm{a}}\right)\end{array}$ & $20 / 382(5.2)$ & $9 / 389(2.3)$ & 0.050 \\
Transient RLN paralysis & $87 / 605(14.4)$ & $55 / 605(9.1)$ & 0.006 \\
Permanent RLN & $5 / 605(0.8)$ & $1 / 605(0.2)$ & 0.219 \\
$\quad$ paralysis & & & \\
Postoperative bleeding & $1 / 605(0.2)$ & $0 / 605(0)$ & $>0.999$ \\
Tracheal injury & $1 / 605(0.2)$ & $0 / 605(0)$ & $>0.999$ \\
Esophageal injury & $0 / 605(0)$ & $0 / 605(0)$ & $\mathrm{NS}$ \\
Wound infection & $4 / 605(0.7)$ & $3 / 605(0.5)$ & 0.997 \\
Horner's syndrome & $2 / 605(0.3)$ & $2 / 605(0.3)$ & $>0.999$ \\
Skin injury/burn & $2 / 605(0.3)$ & $0 / 605(0)$ & $>0.999$ \\
Pneumothorax & $1 / 605(0.2)$ & $0 / 605(0)$ & $>0.999$ \\
Conversion to open & $1 / 605(0.2)$ & $0 / 605(0)$ & $>0.999$ \\
$\quad$ surgery & & & \\
\hline
\end{tabular}

Values are presented as number (\%).

$\mathrm{ET}$, endoscopic thyroidectomy; RT, robotic thyroidectomy; RLN, recurrent laryngeal nerve.

${ }^{\text {a) }} \mathrm{PTH}<15 \mathrm{ng} / \mathrm{mL}$. 
Table 4. Comparison of operation times $(\mathrm{min})^{\mathrm{a})}$

\begin{tabular}{lcccccc}
\hline \multirow{2}{*}{ Variable } & \multicolumn{2}{c}{ Overall } & & \multicolumn{3}{c}{ Propensity score matching } \\
\cline { 2 - 3 } & ET $(\mathrm{n}=1,029)$ & RT $(\mathrm{n}=2,003)$ & P-value & ET $(\mathrm{n}=605)$ & RT $(\mathrm{n}=605)$ & P-value \\
\hline Total thyroidectomy only & $149.7 \pm 37.6$ & $116.1 \pm 36.8$ & 0.015 & $147.1 \pm 38.3$ & $117.5 \pm 39.5$ & 0.031 \\
Total thyroidectomy with CND & $165.3 \pm 38.1$ & $121.6 \pm 41.6$ & 0.027 & $171.3 \pm 35.2$ & $120.4 \pm 39.6$ & 0.019 \\
Total thyroidectomy with CND and LND & $259.4 \pm 69.1$ & $241.5 \pm 78.3$ & 0.284 & $271.2 \pm 73.3$ & $240.6 \pm 72.2$ & 0.107 \\
Subtotal or lobectomy & $135.7 \pm 49.6$ & $98.7 \pm 34.1$ & 0.035 & $126.5 \pm 51.7$ & $92.1 \pm 36.9$ & 0.016 \\
Completion lobectomy & $115.0 \pm 39.1$ & $98.1 \pm 49.0$ & 0.067 & - & - & -
\end{tabular}

ET, endoscopic thyroidectomy; RT, robotic thyroidectomy; CND, central neck dissection; LND, lateral neck dissection.

${ }^{\text {a) }}$ From skin incision to skin closure.

Table 5. Comparison of surgical completeness after first radioiodine (RAI) ablation

\begin{tabular}{|c|c|c|c|c|c|c|}
\hline \multirow{2}{*}{ Variable } & \multicolumn{3}{|c|}{ Overall } & \multicolumn{3}{|c|}{ Propensity score matching } \\
\hline & ET $(n=1,029)$ & RT $(\mathrm{n}=2,003)$ & P-value & $\mathrm{ET}(\mathrm{n}=605)$ & RT $(n=605)$ & P-value \\
\hline $\begin{array}{l}\text { No. of patients who underwent RAI } \\
\text { ablation }{ }^{\text {a) }}\end{array}$ & $\begin{array}{c}326 / 726 \\
(44.9)\end{array}$ & $\begin{array}{l}950 / 1,728 \\
(54.9)\end{array}$ & NS & $\begin{array}{c}175 / 382 \\
(45.8)\end{array}$ & $\begin{array}{c}191 / 389 \\
(49.1)\end{array}$ & NS \\
\hline $\begin{array}{l}\text { Stimulated-Tg after first RAI ablation } \\
(\mathrm{ng} / \mathrm{mL})\end{array}$ & $\begin{array}{c}1.64 \\
(<0.2-55.1)\end{array}$ & $\begin{array}{c}0.71 \\
(<0.2-79.8)\end{array}$ & 0.021 & $\begin{array}{c}1.55 \\
(<0.2-55.1)\end{array}$ & $\begin{array}{c}0.58 \\
(<0.2-47.2)\end{array}$ & 0.009 \\
\hline $\begin{array}{l}\text { No. of patients with stimulated-Tg } \\
<1.0 \mathrm{ng} / \mathrm{mL} \text { after first RAI ablation }\end{array}$ & $\begin{array}{c}196 / 326 \\
(60.1)\end{array}$ & $\begin{array}{c}863 / 950 \\
(90.8)\end{array}$ & $<0.001$ & $\begin{array}{c}113 / 175 \\
(64.6)\end{array}$ & $\begin{array}{c}177 / 191 \\
(92.7)\end{array}$ & $<0.001$ \\
\hline
\end{tabular}

Values are presented as number (\%) or median (range).

ET, endoscopic thyroidectomy; RT, robotic thyroidectomy; $\mathrm{Tg}$, thyroglobulin.

${ }^{a)}$ In patients with total thyroidectomy due to differentiated thyroid cancer.

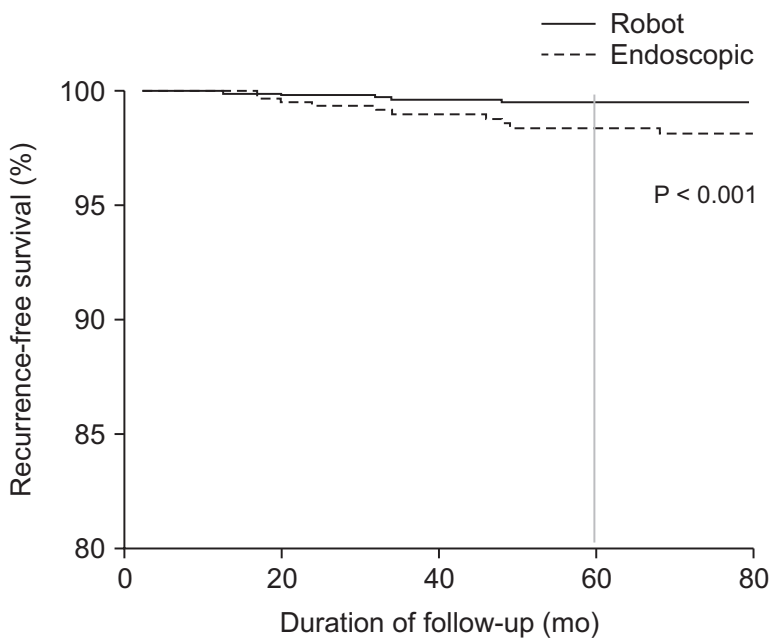

Fig. 1. Recurrence-free survival of propensity scorematched patients with malignancy $(E T=408, R T=407)$. $E T$, endoscopic thyroidectomy; RT, robotic thyroidectomy.

patients (1.4\%) in the ET group and 5 patients of $407(0.3 \%)$ in the RT group experienced recurrence of malignancy $(\mathrm{P}<0.001)$. In the ET group, 3 cases were recurred in the contralateral lobe, 3 cases in the operative bed, 4 cases in the lateral neck lymph nodes. In the RT group, 2 cases were recurred in the contralateral lobe, 2 cases in the operative bed, 1 case in the lateral neck lymph nodes. The 5-year recurrence-free survival rates were $98.7 \%$ in the ET group and $99.7 \%$ in the RT group (P $<0.001$ ) (Fig. 1).

\section{DISCUSSION}

The incidence of thyroid cancer had been increasing markedly worldwide. This increase may be due primarily to increases in screening rates, although the exact cause has not yet been determined [15]. Indications for thyroid surgery have also been expanding to include various benign thyroid diseases, as well as thyroid cancer. For example, thyroidectomy is performed on patients with uncontrolled Graves' disease, huge nodular hyperplasia, and follicular neoplasm, which cannot be determined by fine needle aspiration cytology [16]. Because conventional thyroid surgery cannot avoid making an anterior collar incision, scarring is of great concern, especially in young female patients. Methods to reduce surgical scarring in thyroid surgery include minimally invasive video-assisted thyroidectomy, video-assisted neck surgery $[17,18]$, scarless endoscopic thyroidectomy [19], and BABA and transaxillary methods [5,20].

Surgical outcomes have been reported for 512 patients who 
underwent BABA ET and 1,026 who underwent BABA RT at our institution $[6,12]$. One of the primary advantages of BABA is the symmetric surgical view exposing clear anatomic markers, allowing surgeons to operate in equivalent circumstances on both sides of the thyroid glands. Moreover, the BABA methods of ET and RT have demonstrated feasibility and surgical completeness $[7,9,10,21,22]$. BABA was associated with low rates of postoperative complications and recurrence, as well as satisfaction with cosmetic outcomes.

The current study was performed to compare the surgical outcomes and completeness of ET and RT using BABA methods. Prior to propensity score matching, the BABA ET and RT groups differed significantly in gender distribution, the extent of the operation, pathologic characteristics, number of central lymph nodes, and recurrence rates. Following propensity score matching based on 9 covariates, the 2 groups did not differ significantly in the above characteristics. Thus, propensity score matching balanced the covariates and minimized the baseline discrepancies between the 2 groups.

A comparison of postsurgical complications showed that rates of postoperative hypoparathyroidism and RLN paralysis were lower in the BABA RT than in the BABA ET group, both before and after propensity score matching. Rates of permanent hypoparathyroidism and transient RLN paralysis were significantly lower in the BABA RT than the BABA ET group. Rates of transient hypoparathyroidism were similar in both groups, and it was probably due to the thorough central neck dissection according to the policy of our institute. Rates of wound infection were also significantly lower in the RT group before matching, but the percentages after matching were too low to assess statistical differences. Although all other surgical complications, such as postoperative bleeding, adjacent organ injury, skin injury, and conversion to open surgery, did not differ significantly in the 2 groups, the rate of each in the RT group was equal to or lower than the rate in the ET group. Operation time was significantly shorter in the BABA RT than in the BABA ET group, both before and after matching, regardless of the extent of surgery and despite the time required for robot docking and exchanging robot arms in BABA RT. The time required for total thyroidectomy plus lateral neck dissection did not differ significantly in the ET and RT groups, perhaps due to the additional procedure required for lateral traction of the sternocleidomastoid muscle.

Surgical completeness of ET and RT was assessed by measuring serum Tg level, especially stimulated-Tg level after first RAI ablation therapy in cancer patients. The serum concentration of stimulated-Tg is considered a reliable indicator of remnant thyroid tissue after total thyroidectomy. The median stimulated-Tg concentration after first ablation therapy was significantly lower in the RT than in the ET group. More importantly, the percentage of patients with stimulated-Tg levels $<1.0 \mathrm{ng} / \mathrm{mL}$, an indicator of successful treatment, was significantly higher in the RT group, both before and after propensity score matching. At a long-term, 5-year follow-up, the recurrence rates in the 2 groups were low and similar to those reported previously [5,23]. A comparison of the 2 groups showed that the rate of recurrence of malignant thyroid disease was lower in the RT group, with 5-year recurrence-free survival rates of $99.7 \%$ in the RT group and $98.7 \%$ in the ET group.

There were a few concerns about utilizing the BABA for thyroid surgery. The first was the possibility of postoperative chest paresthesia due to the skin flap made underneath the anterior chest wall during the BABA operation. However, sensory impairment of the anterior chest was reported to be temporary, improving within 3 months after surgery [24,25]. Indeed, none of the patients in the current study complained of chest paresthesia 3 months after surgery. Another concern about $\mathrm{BABA}$ regarded the complications related to $\mathrm{CO}_{2}$ toxicity [26]. $\mathrm{CO}_{2}$ insufflation in the neck has been reported to cause serious problems, including subcutaneous emphysema, pneumomediastinum, and absorption of $\mathrm{CO}_{2}$ into the bloodstream. However, insufflations of up to $9 \mathrm{mmHg}$ of $\mathrm{CO}_{2}$ has been regarded as safe from the complications of toxicity $[27,28]$. Furthermore, a low insufflations pressure, of 5-6 $\mathrm{mmHg}$, was regarded as sufficient to visualize the surgical field, and none of patients in this study experienced any of the above complications. Finally, concerns were raised about tumor dissemination during specimen removal, but this could be resolved by using an endoscopic bag through the axillary port.

The current study had several limitations, including its retrospective design. Prospective, randomized controlled trials are required to determine the superiority of BABA RT over BABA ET. In addition, most surgeons who took part in this study had experience with ET prior to gaining experience with RT. This may have affected operating times and surgical completeness.

In conclusion, BABA ET and RT are safe and effective methods of managing various thyroid diseases. Use of the robotic system, however, may help overcome the limitations of instruments and surgeon's skill, especially in patients with malignant diseases.

\section{ACKNOWLEDGEMENTS}

\section{Conflict of Interest}

No potential conflict of interest relevant to this article was reported.

\section{ORCID iD}

June Young Choi: https://orcid.org/0000-0001-9990-607X

In Eui Bae: https://orcid.org/0000-0002-9220-8815

Jin Wook Yi: https://orcid.org/0000-0002-9296-8443

Hyeong Won Yu: https://orcid.org/0000-0001-7338-5157 
Su-jin Kim: https://orcid.org/0000-0001-5511-3596

Young Jun Chai: https://orcid.org/0000-0001-8830-3433

Kyu Eun Lee: https://orcid.org/0000-0002-2354-3599

Yeo-Kyu Youn: https://orcid.org/0000-0003-2349-4624

Author Contribution

Conceptualization: KEL, YKY
Formal Analysis: IEB, JYC, HWY, YJC

Investigation: IEB, JYC, KEL

Methodology: HSK, SGY, JWY. SK

Project Administration: YJC, YKY

Writing - Original Draft: IEB, JYC, KEL, SK

Writing - Review \& Editing: HSK, SGY, JWY, HWY, YJC, YKY

\section{REFERENCES}

1. Gagner M. Endoscopic subtotal parathyroidectomy in patients with primary hyperparathyroidism. Br J Surg 1996;83:875.

2. Ikeda Y, Takami H, Sasaki Y, Takayama J, Niimi M, Kan S. Comparative study of thyroidectomies. Endoscopic surgery versus conventional open surgery. Surg Endosc 2002;16:1741-5.

3. Shimazu K, Shiba E, Tamaki Y, Takiguchi S, Taniguchi E, Ohashi S, et al. Endoscopic thyroid surgery through the axillobilateral-breast approach. Surg Laparosc Endosc Percutan Tech 2003;13:196-201.

4. Lombardi CP, Raffaelli M, Princi P, De Crea C, Bellantone R. Video-assisted thyroidectomy: report of a 7-year experience in Rome. Langenbecks Arch Surg 2006;391:174-7.

5. Choe JH, Kim SW, Chung KW, Park KS, Han W, Noh DY, et al. Endoscopic thyroidectomy using a new bilateral axillobreast approach. World J Surg 2007;31:6016.

6. Lee KE, Kim E, Koo DH, Choi JY, Kim KH, Youn YK. Robotic thyroidectomy by bilateral axillo-breast approach: review of 1,026 cases and surgical completeness. Surg Endosc 2013;27:2955-62.

7. Kim WW, Kim JS, Hur SM, Kim SH, Lee $\mathrm{SK}, \mathrm{Choi} \mathrm{JH}$, et al. Is robotic surgery superior to endoscopic and open surgeries in thyroid cancer? World J Surg 2011;35:779-84.

8. Lee KE, Rao J, Youn YK. Endoscopic thyroidectomy with the da Vinci robot system using the bilateral axillary breast approach (BABA) technique: our initial experience. Surg Laparosc Endosc Percutan Tech 2009;19:e71-5.

9. Chung YS, Choe JH, Kang KH, Kim SW, Chung KW, Park KS, et al. Endoscopic thyroidectomy for thyroid malignancies: comparison with conventional open thyroidectomy. World J Surg 2007;31:23026.

10. Lee KE, Koo DH, Im HJ, Park SK, Choi JY, Paeng JC, et al. Surgical completeness of bilateral axillo-breast approach robotic thyroidectomy: comparison with conventional open thyroidectomy after propensity score matching. Surgery 2011;150:1266-74.

11. He QQ, Zhu J, Zhuang DY, Fan ZY, Zheng LM, Zhou P, et al. Comparative study between robotic total thyroidectomy with central lymph node dissection via bilateral axillo-breast approach and conventional open procedure for papillary thyroid microcarcinoma. Chin Med J (Engl) 2016;129:2160-6.

12. Choi JY, Lee KE, Chung KW, Kim SW, Choe JH, Koo DH, et al. Endoscopic thyroidectomy via bilateral axillo-breast approach (BABA): review of 512 cases in a single institute. Surg Endosc 2012;26:94855.

13. Kwon H, Koo do H, Choi JY, Kim E, Lee KE, Youn YK. Bilateral axillo-breast approach robotic thyroidectomy for Graves' disease: an initial experience in a single institute. World J Surg 2013:37:1576-81.

14. Amin MB, Edge S, Greene F, Byrd DR, Brookland RK, Washington MK, et al. (Eds.). AJCC Cancer Staging Manual (8th edition). Springer International
Publishing: American Joint Commission on Cancer. 2017.

15. Mehra S, Tuttle RM, Milas M, Orloff L, Bergman D, Bernet V, et al. Database and registry research in thyroid cancer: striving for a new and improved national thyroid cancer database. Thyroid 2015:25:157-68.

16. Haugen BR, Alexander EK, Bible KC, Doherty GM, Mandel SJ, Nikiforov YE, et al. 2015 American Thyroid Association Management Guidelines for Adult Patients with Thyroid Nodules and Differentiated Thyroid Cancer: The American Thyroid Association Guidelines Task Force on Thyroid Nodules and Differentiated Thyroid Cancer. Thyroid 2016;26:1-133.

17. Miccoli P, Berti P, Bendinelli C, Conte M, Fasolini F, Martino E. Minimally invasive video-assisted surgery of the thyroid: a preliminary report. Langenbecks Arch Surg 2000;385:261-4.

18. Shimizu K, Akira S, Jasmi AY, Kitamura Y, Kitagawa W, Akasu H, et al. Video-assisted neck surgery: endoscopic resection of thyroid tumors with a very minimal neck wound. J Am Coll Surg 1999;188:697-703.

19. Ohgami M, Ishii S, Arisawa Y, Ohmori T, Noga K, Furukawa T, et al. Scarless endoscopic thyroidectomy: breast approach for better cosmesis. Surg Laparosc Endosc Percutan Tech 2000;10:14.

20. Yoon JH, Park CH, Chung WY. Gasless endoscopic thyroidectomy via an axillary approach: experience of 30 cases. Surg Laparosc Endosc Percutan Tech 
2006;16:226-31.

21. Jackson NR, Yao L, Tufano RP, Kandil EH. Safety of robotic thyroidectomy approaches: meta-analysis and systematic review. Head Neck 2014:36:137-43.

22. Koo DH, Kim DM, Choi JY, Lee KE, Cho $\mathrm{SH}$, Youn YK. In-depth survey of scarring and distress in patients undergoing bilateral axillo-breast approach robotic thyroidectomy or conventional open thyroidectomy. Surg Laparosc Endosc Percutan Tech 2015:25:436-9.

23. Sherman SI. Thyroid carcinoma. Lancet 2003;361:501-11.

24. Kim SJ, Lee KE, Myong JP, Kwon MR,
Youn YK. Recovery of sensation in the anterior chest area after bilateral axillobreast approach endoscopic/robotic thyroidectomy. Surg Laparosc Endosc Percutan Tech 2011;21:366-71.

25. Kim SJ, Lee KE, Myong JP, Koo DH, Lee J, Youn YK. Prospective study of sensation in anterior chest areas before and after a bilateral axillo-breast approach for endoscopic/robotic thyroid surgery. World J Surg 2013;37:1147-53.

26. Kandil E, Hammad AY, Walvekar RR, Hu T, Masoodi H, Mohamed SE, et al. Robotic thyroidectomy versus nonrobotic approaches: a meta-analysis examining surgical outcomes. Surg Innov 2016;23:31725.

27. Kim HY, Choi YJ, Yu HN, Yoon SZ. Optimal carbon dioxide insufflation pressure during robot-assisted thyroidectomy in patients with various benign and malignant thyroid diseases. World J Surg Oncol 2012;10:202.

28. Kim JA, Kim JS, Chang MS, Yoo YK, Kim DK. Influence of carbon dioxide insufflation of the neck on intraocular pressure during robot-assisted endoscopic thyroidectomy: a comparison with open thyroidectomy. Surg Endosc 2013;27:158793. 